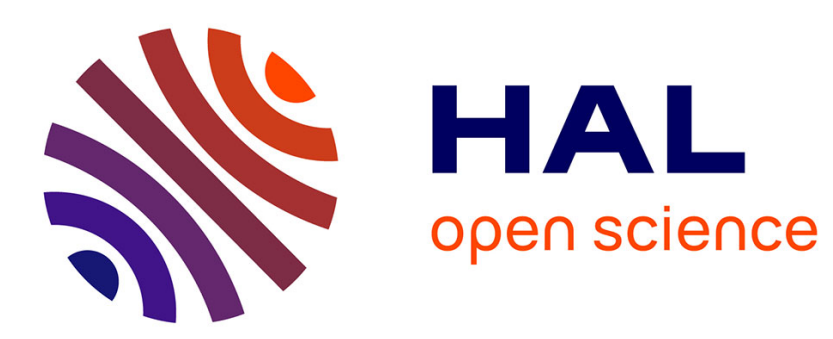

\title{
Analysis of radius-periodic cylindrical structures
}

\author{
Halim Boutayeb, Kouroch Mahdjoubi, Anne-Claude Tarot
}

\section{To cite this version:}

Halim Boutayeb, Kouroch Mahdjoubi, Anne-Claude Tarot. Analysis of radius-periodic cylindrical structures. Aug 2003, pp. 813-816, 10.1109/APS.2003.1219359 . hal-00133732

\section{HAL Id: hal-00133732 \\ https://hal.science/hal-00133732}

Submitted on 27 Feb 2007

HAL is a multi-disciplinary open access archive for the deposit and dissemination of scientific research documents, whether they are published or not. The documents may come from teaching and research institutions in France or abroad, or from public or private research centers.
L'archive ouverte pluridisciplinaire HAL, est destinée au dépôt et à la diffusion de documents scientifiques de niveau recherche, publiés ou non, émanant des établissements d'enseignement et de recherche français ou étrangers, des laboratoires publics ou privés. 


\title{
Analysis of Radius-Periodic Cylindrical Structures
}

\author{
H. Boutayeb, K. Mahdjoubi and A.C. Tarot \\ IETR - Institut d'Electronique et de Télécommunication de Rennes, Université de \\ Rennes 1, Bât. 11 C, Campus de Beaulieu, 35042 Rennes - France
}

\begin{abstract}
The purpose of this communication is to present an analysis method for cylindrical structure witch are periodic along their radii and are excited by a line source placed in the center. At first, we derive analytical formulas for the transmitted wave and the wave inside the structure of a single layer cylindrical structure, which allow to extract the characteristics of the cylindrical layer. Then we obtain the dispersion equation and the transmission coefficient of multiple layer periodic structures.
\end{abstract}

\section{I - Introduction}

There is an important recent interest in periodic structures associated with microwave antennas and devices. Cylindrical periodic structures are however not enough used, probably because their properties are not well known and their behavior not well analyzed. In this paper, we propose an analysis method that allows to obtain the main characteristics of these structures.

In part II, we consider a single cylindrical shell, for which we extract the reflection and transmission coefficients when the incident wave is an outgoing cylindrical one. Using these results, we analyze in part III, the multiple layer periodic structures and give the (approximate) expression of their dispersion equation.

\section{II - Characterization of a single cylindrical surface}

Consider the structure of figure 1, where a line source is placed in the center of the cavity constituted by a cylindrical surface. The structure is characterized by the radius $\mathbf{C}$, the (complex) reflection and transmission coefficients $\left(\mathbf{r}=|\mathbf{r}| \cdot \exp \left(\mathbf{j} \varphi_{\mathbf{r}}\right), \mathbf{t}\right)$ of the cylindrical surface and the reflection coefficient $\mathbf{r}_{\mathbf{a}}$ of the central line.

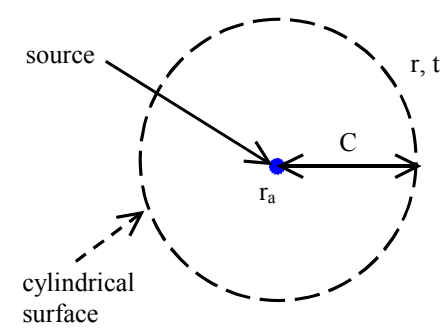

Figure 1 : Line source in the center of a cylindrical surface

Our aim is now to obtain the characteristic parameters $\mathbf{r}$ and $\mathbf{t}$ of the cylindrical surface from the knowledge of $\mathbf{T}$ and $\mathbf{R}$ (figures 2), the "total" transmission and reflection coefficients of the cylindrical cavity for the uniform cylindrical wave. There is multiple wave reflections between the surface and the central line as in the plane structure case [1].
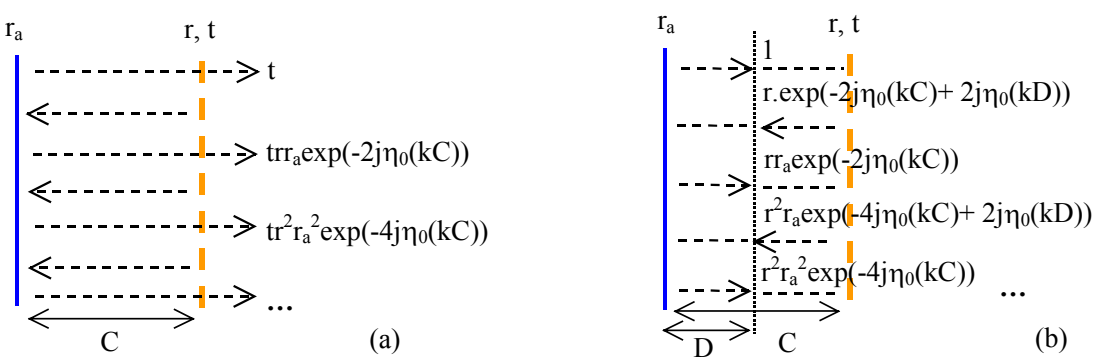

Figures 2:(a) : Partial terms of the "total" transmission coefficient $\boldsymbol{T}(b)$ : Partial terms of the "total" reflection coefficient $\boldsymbol{R}$ inside the cavity

The transmission coefficient $\mathbf{T}$ is defined as the ratio of the total waves transmitted outside the cavity, to the incident wave expressed by the first order Hankel function $\mathrm{H}_{0}{ }^{2}(\mathrm{k} \rho)=\left|\mathrm{H}_{0}{ }^{2}(\mathrm{k} \rho)\right| \cdot \mathrm{e}^{-\mathrm{j} \eta_{0}(\mathrm{k} \rho)}$. T can be expressed in terms of $(\mathrm{r}, \mathrm{t})$ and $\mathrm{r}_{\mathrm{a}}$ (see figure $\left.2 a\right)$ : 


$$
\mathrm{T}=\mathrm{t} \sum_{\mathrm{n}=0}^{+\infty} \mathrm{r}^{\mathrm{n}} \mathrm{r}_{\mathrm{a}}{ }^{\mathrm{n}} \exp \left(-\mathrm{jn} 2 \eta_{0}(\mathrm{kC})\right)=\frac{\mathrm{t}}{1-\mathrm{rr}_{\mathrm{a}} \exp \left(-\mathrm{j} 2 \eta_{0}(\mathrm{kC})\right)}, \text { where } \eta_{0}(\mathrm{x})=\arctan \left(\frac{\mathrm{N}_{0}(\mathrm{x})}{\mathrm{J}_{0}(\mathrm{x})}\right)
$$

$\mathrm{J}_{0}(\mathrm{x})$ and $\mathrm{N}_{0}(\mathrm{x})$ are the Bessel functions of order 0 , and $\mathbf{k}$ is the free space wave number.

Let us call $\mathbf{R}$ the wave at a distance $\mathrm{D}$ from the line source inside the cavity, normalized by the incident wave (figure $2 b$ ). It can be expressed in terms of $(r, t)$ and $r_{a}$ :

$$
\mathrm{R}=\frac{1+\mathrm{r} \cdot \exp \left(-\mathrm{j} 2 \eta_{0}(\mathrm{kC})\right) \exp \left(\mathrm{j} 2 \eta_{0}(\mathrm{kD})\right)}{1-\mathrm{rr}_{\mathrm{a}} \exp \left(-\mathrm{j} 2 \eta_{0}(\mathrm{kC})\right)}
$$

With expressions (1) and (2), we can calculate the reflection and transmission coefficients $(\mathrm{r}, \mathrm{t})$ if we know $\mathrm{R}$ and $\mathrm{T}$ :

$$
r=\frac{R-1}{\left(r_{a} R+B_{2}\right) B_{1}} \quad, \quad t=T\left(1-r_{a} B_{1}\right)
$$

where

$$
\mathrm{B}_{1}=\exp \left(-2 \mathrm{j} \eta_{0}(\mathrm{kC})\right) \quad, \quad \mathrm{B}_{2}=\exp \left(2 \mathrm{j} \eta_{0}(\mathrm{kD})\right)
$$

In the example bellow the coefficients $\mathrm{R}$ and $\mathrm{T}$ are obtained by FDTD method, where the incident wave is created by an infinite line of current sources for witch $r_{a}=1$ (virtual source).

Let us consider now an example of cylindrical surface composed of periodic infinitely long metallic wires of diameter $\mathbf{a}$. $\quad \mathbf{P}_{\theta}$ is the angular period and $\mathbf{P}_{\mathbf{t}}$ is the transversal period $\left(\mathrm{P}_{\mathrm{t}}=\mathrm{P}_{\theta} * \mathrm{C}\right)$. Figure 3 gives the magnitude of the reflection and transmission coefficients $(\mathbf{r}, \mathbf{t})$ of a metallic wire cylindrical surface versus normalized frequency $\mathrm{P}_{\mathrm{t}} / \lambda$, where $\mathbf{a}=2 \mathrm{~mm}$ and $\mathbf{P}_{\mathrm{t}}=\mathrm{pi} / 6 * 200 \mathrm{~mm} \approx 105 \mathrm{~mm}$. The coefficients $(\mathbf{r}, \mathbf{t})$ are obtained from $\mathbf{R}$ and $\mathbf{T}$ (evaluated by FDTD method) by using formulas (3) and (4). Figure 4 shows that the resonances of $|\mathrm{T}|$ are well foreseen by the condition $2 \eta_{0}(\mathrm{kC})+2 \mathrm{n} \pi=\varphi_{\mathrm{r}}(\mathrm{n}=0,1 \ldots)$ in formula (1). It is also verified that the boundary condition $r+1=t$ is satisfied. These facts validate the method of extraction of $(r, t)$ proposed here.

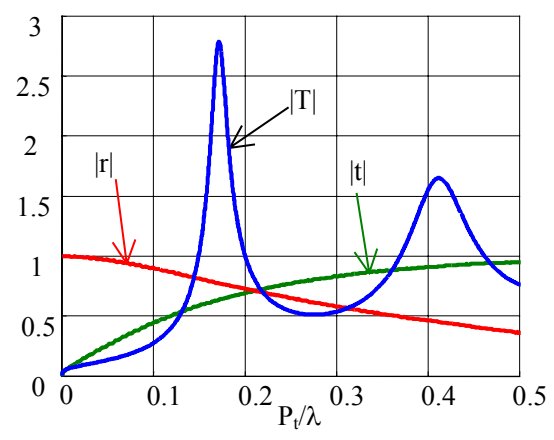

Figure 3 : Cylindrical periodic surface of metallic wires $(\boldsymbol{C}=200 \mathrm{~mm}, \boldsymbol{a}=2 \mathrm{~mm}$, $\left.\boldsymbol{P}_{\boldsymbol{\theta}}=30^{\circ}, \boldsymbol{P}_{\boldsymbol{t}}=\mathrm{pi} / 6 * 200 \mathrm{~mm} \approx 105 \mathrm{~mm}\right)$

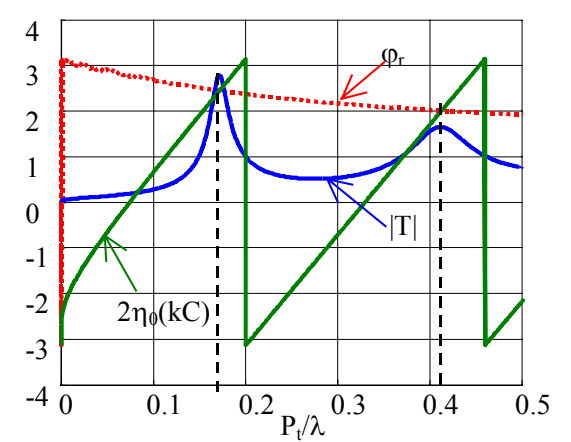

Figure $4:$ Resonances of $T$ (intersections between $\varphi_{r}$ and $2 \eta_{0}(k C)$.

\section{III - Multiple layer periodic cylindrical structure and dispersion equation}

The method of the previous part is applied to obtain the transmission coefficient $\mathbf{t}$ of a cylindrical surface of periodic metallic wires, for different values of the radius $\mathrm{C}$ (Figure 5). The transverse period $P_{t}$ is maintained constant by varying appropriately the angular period $\mathrm{P}_{\theta}$. One can see that for $\mathrm{C}$ sufficiently large, surfaces with the same $\mathrm{P}_{\mathrm{t}}$ have the same coefficient $|t|$. In fact, the surfaces of the same Pt have the same characteristics $(r, t)$ for sufficiently large $\mathrm{C}$.

Figure 6 presents a multiple layer periodic cylindrical structure where the radial period $\mathbf{P}_{\mathbf{r}}$ is the distance between two successive surfaces and $\mathbf{C}_{\mathbf{1}}$ is the radius of the first layer.

In a first example, we take $\mathrm{C}_{1}=\mathrm{P}_{\mathrm{r}}$. One the other hand, the surfaces have all the same transversal period $\mathrm{P}_{\mathrm{t}}$ (so approximately the same $(\mathbf{r}, \mathbf{t})$ ). Figure 7 shows the magnitude of 
the transmission coefficient $T_{i}$ for $i=1,2$ and 3 layer periodic structure of metallic wires. One can notice that the number of frequency resonance picks is equal to the number of cavities.

Figure 8 gives the transmission line model of the $n^{\text {th }}$ layer $(n=0,1,2 \ldots)$ of the cylindrical periodic structure where in each side of the equivalent admittance $y_{n}$ of the surface, there is two non-uniform lines of length $\mathrm{P}_{\mathrm{r}} / 2$.

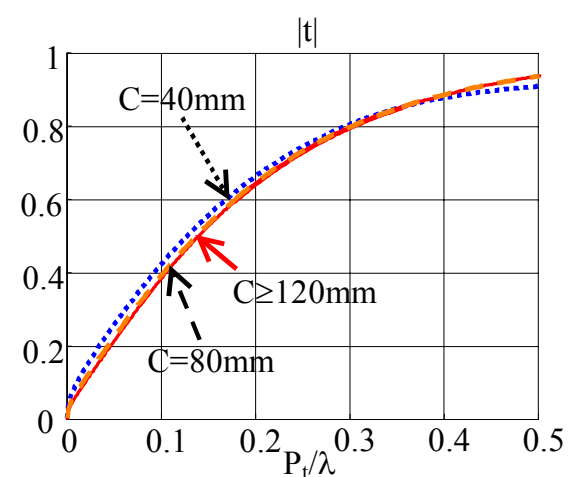

Figure 5 : Magnitude of $\boldsymbol{t}$ for periodic surface of metallic wires for several values of $\boldsymbol{C},\left(\boldsymbol{a}=1 \mathrm{~mm}, \boldsymbol{P}_{\boldsymbol{t}}=\mathrm{pi} / 6 * 40 \mathrm{~mm}\right)$.

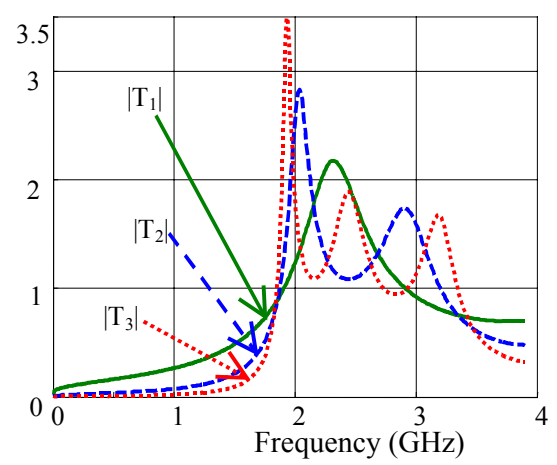

Figure $7:\left|T_{i}\right|$ for $i=1,2$ and 3 layers periodic structure of metallic wires

$\left(\boldsymbol{C}_{\boldsymbol{1}}=\boldsymbol{P}_{\boldsymbol{r}}=40 \mathrm{~mm}, \boldsymbol{a}=1 \mathrm{~mm}, \boldsymbol{P}_{\boldsymbol{\theta} i}=60 \% /, i=1,2 \ldots\right.$ $\boldsymbol{P}_{\boldsymbol{t}}=40 \mathrm{~mm} * \mathrm{pi} / 3 \approx 41.9 \mathrm{~mm}$ )

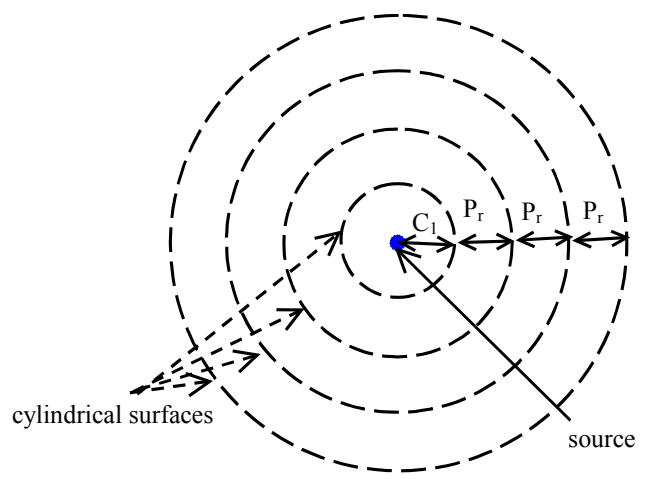

Figure 6 : Multiple layer periodic cylindrical structure

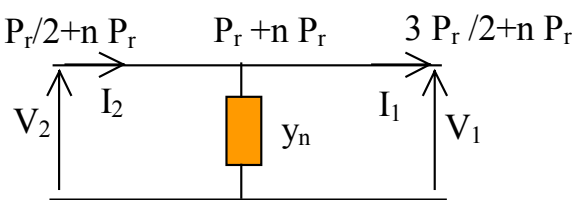

Figure 8: Transmission line model of the $n^{\text {th }}$ surface of the cylindrical periodic structure $(n=0,1 .$.

The chain matrix of the quadripole of figure 8 can be written:

$$
\left[\begin{array}{l}
\mathrm{V}_{2} \\
\mathrm{I}_{2}
\end{array}\right]=\left[\begin{array}{ll}
\mathrm{a}_{1} & \mathrm{~b}_{1} \\
\mathrm{c}_{1} & \mathrm{~d}_{1}
\end{array}\right]\left[\begin{array}{cc}
1 & 0 \\
\mathrm{y}_{\mathrm{n}} & 1
\end{array}\right]\left[\begin{array}{ll}
\mathrm{a}_{2} & \mathrm{~b}_{2} \\
\mathrm{c}_{2} & \mathrm{~d}_{2}
\end{array}\right]\left[\begin{array}{l}
\mathrm{V}_{1} \\
\mathrm{I}_{1}
\end{array}\right]=\left[\begin{array}{ll}
\mathrm{E} & \mathrm{F} \\
\mathrm{G} & \mathrm{H}
\end{array}\right]\left[\begin{array}{l}
\mathrm{V}_{1} \\
\mathrm{I}_{1}
\end{array}\right]
$$

Where the coefficients $a_{1}, a_{2}, b_{1}, b_{2}, c_{1}, c_{2}, d_{1}, d_{2}$ are combinations of Bessel functions (see [2]). As an example, $a_{1}$ coefficient is given bellow:

$$
\mathrm{a}_{1}=\frac{\pi \mathrm{k}\left(\mathrm{P}_{\mathrm{r}}+\mathrm{nP} \mathrm{P}_{\mathrm{r}}\right)}{2}\left[\mathrm{~J}_{1}\left(\mathrm{k}\left(\mathrm{P}_{\mathrm{r}}+\mathrm{nP}_{\mathrm{r}}\right)\right) \mathrm{N}_{0}\left(\mathrm{k}\left(\mathrm{P}_{\mathrm{r}} / 2+\mathrm{nP}_{\mathrm{r}}\right)\right)-\mathrm{J}_{0}\left(\mathrm{k}\left(\mathrm{P}_{\mathrm{r}} / 2+\mathrm{nP}_{\mathrm{r}}\right)\right) \mathrm{N}_{1}\left(\mathrm{k}\left(\mathrm{P}_{\mathrm{r}}+\mathrm{nP}_{\mathrm{r}}\right)\right)\right]
$$

We suppose that the outgoing cylindrical wave propagates through the infinite structure with a constant of propagation $\beta$ such that $V_{2}=\lambda_{V} V_{1}$ and $I_{2}=\lambda_{I} I_{1}$ (cylindrical equivalent for Floquet theorem) :

$$
\left[\begin{array}{cc}
\mathrm{E} & \mathrm{F} \\
\mathrm{G} & \mathrm{H}
\end{array}\right]\left[\begin{array}{c}
\mathrm{V}_{1} \\
\mathrm{I}_{1}
\end{array}\right]=\left[\begin{array}{cc}
\lambda_{\mathrm{V}} & 0 \\
0 & \lambda_{\mathrm{I}}
\end{array}\right]\left[\begin{array}{c}
\mathrm{V}_{1} \\
\mathrm{I}_{1}
\end{array}\right] \text {, where } \lambda_{\mathrm{V}}=\frac{\mathrm{H}_{0}^{2}\left(\beta\left(\mathrm{P}_{\mathrm{r}} / 2+\mathrm{nP}_{\mathrm{r}}\right)\right)}{\mathrm{H}_{0}^{2}\left(\beta\left(3 \mathrm{P}_{\mathrm{r}} / 2+\mathrm{nP}_{\mathrm{r}}\right)\right)}, \lambda_{\mathrm{I}}=\frac{\mathrm{H}_{1}^{2}\left(\beta\left(\mathrm{P}_{\mathrm{r}} / 2+\mathrm{nP}_{\mathrm{r}}\right)\right)}{\mathrm{H}_{1}^{2}\left(\beta\left(3 \mathrm{P}_{\mathrm{r}} / 2+\mathrm{nP}_{\mathrm{r}}\right)\right)}
$$

The dispersion equation becomes :

$$
\lambda_{\mathrm{V}} \lambda_{\mathrm{I}}-\lambda_{\mathrm{V}} \mathrm{H}-\lambda_{\mathrm{I}} \mathrm{E}=\mathrm{FG}-\mathrm{EH}
$$


This equation depends on the layer number $\mathbf{n}$ and it is not evident that there is a unique $\beta$ for all $\mathbf{n}$. However, as $\mathbf{n}$ increases, the radial line chain matrix tends to the uniform transmission line chain matrix and $\mathrm{y}_{\mathrm{n}}$ becomes constant and equal to $\mathrm{y}=2(1-\mathrm{t}) / \mathrm{t}$. Therefore, the dispersion equation (8) tends to that of the plane structure case (9). Thus, the equation (9) becomes a first approximation for cylindrical dispersion equation :

$$
\cos \left(\beta \mathrm{P}_{\mathrm{r}}\right)=\cos \left(k \mathrm{P}_{\mathrm{r}}\right)+\mathrm{j} \frac{\mathrm{y}}{2} \sin \left(k \mathrm{P}_{\mathrm{r}}\right)
$$

This equation allows to obtain the $\mathrm{k}-\beta$ diagram (or Brillouin diagram).

In figure 9, we plot the modulus of $\mathrm{M}=\cos \left(\mathrm{kP}_{\mathrm{r}}\right)+\mathrm{jy} / 2 \sin \left(\mathrm{kP}_{\mathrm{r}}\right)$ (formula (9)) and also the magnitude of the reflection coefficient $\mathbf{r}_{6}$ of a six layer structure of metallic wires. A frequency band gap appears when $|\mathrm{M}|>1$ (no real solution for $\beta$ ) where $\left|\mathrm{r}_{6}\right|$ is near one. Figure 10 gives the transmission coefficient $\left|\mathbf{T}_{\mathbf{6}}\right|$ for the six layer structure with $\mathbf{C}_{\mathbf{1}}=\mathbf{P}_{\mathbf{r}}$. $\left|\mathrm{T}_{6}\right|$ has all its frequency picks in the allowed band and it vanishes in the forbidden band. If we take, now, $\mathrm{C}_{1}$ different from $\mathrm{P}_{\mathrm{r}}$, say $\mathbf{C}_{\mathbf{1}}=\mathbf{2} \mathbf{P}_{\mathbf{r}}$ we see that a pick appears within the forbidden band due to the resonance of the first cavity (figure 11).

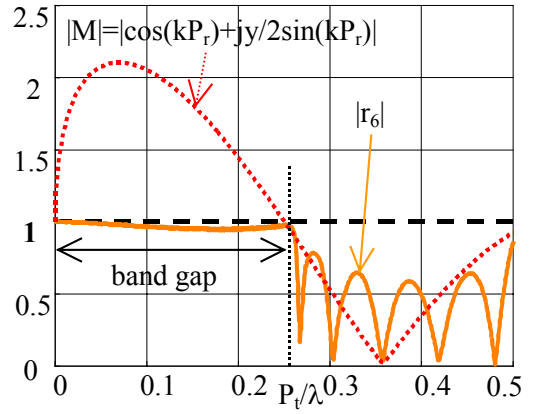

Figure 9 : Six layer cylindrical periodic structure reflection and $M(9) .\left(\boldsymbol{a}=1 \mathrm{~mm}, \boldsymbol{P r}=\boldsymbol{C}_{\boldsymbol{1}}=40 \mathrm{~mm}\right.$ $\boldsymbol{P}_{\boldsymbol{\theta} i}=60 \%$ (i=1,2,...), $\boldsymbol{P}_{\boldsymbol{t}}$ constant $)$

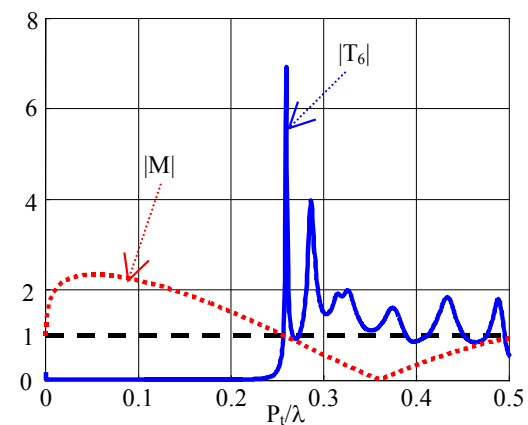

Figure $10:\left|T_{6}\right|$ for six layer structure. $\left(\boldsymbol{a}=1 \mathrm{~mm}, \boldsymbol{P r}=\boldsymbol{C}_{1}=40 \mathrm{~mm}\right)$

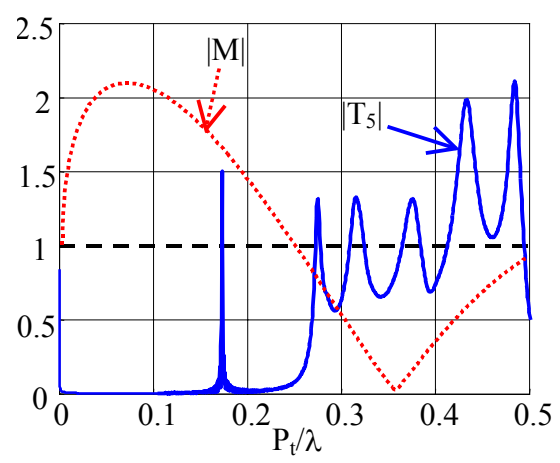

Figure 11 : Five layer cylindrical periodic structure with $\boldsymbol{C}_{\boldsymbol{I}}=2 \boldsymbol{P}_{\boldsymbol{r}}=80 \mathrm{~mm}$

\section{IV - Conclusion}

Analytical expressions are proposed to study periodic cylindrical structures and to obtain there principal characteristics (reflection and transmission coefficients, dispersion equation...). The method can now be applied to analyze the properties (such as frequency or spatial filterings) of these structures. The main property of cylindrical periodic structures is there angular isotropy which allows to obtain better results in many antenna applications such as surface waves suppressing (circular high impedance surfaces), gain enhancement (circular reflectors), etc.

\section{References}

[1] H. Boutayeb, K. Mahdjoubi, A.C Tarot, "Antenna inside PBG and Fabry-Perot cavities “, Journées Internationales de Nice sur les Antennes, JINA, November 2002.

[2] N. Marcuvitz, Waveguide Handbook, p32. New-York 1951 